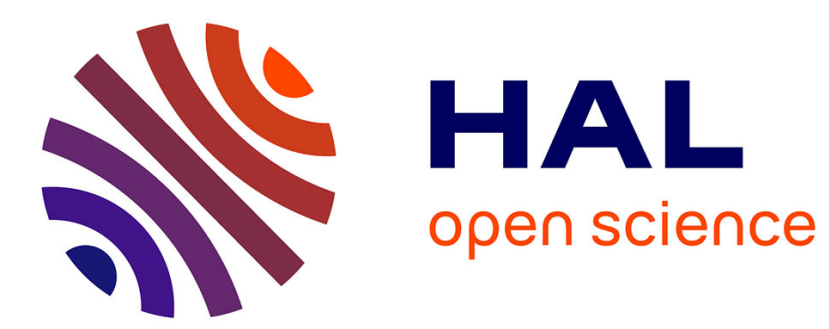

\title{
ULTRASONIC CHARACTERIZATION OF POROSITY USING THE KRAMERS-KRONIG RELATIONS
}

\author{
J.H. Rose, D. Hsu, L. Adler
}

\section{- To cite this version:}

J.H. Rose, D. Hsu, L. Adler. ULTRASONIC CHARACTERIZATION OF POROSITY USING THE KRAMERS-KRONIG RELATIONS. Journal de Physique Colloques, 1985, 46 (C10), pp.C10-787C10-790. 10.1051/jphyscol:198510172 . jpa-00225381

\section{HAL Id: jpa-00225381 https://hal.science/jpa-00225381}

Submitted on 1 Jan 1985

HAL is a multi-disciplinary open access archive for the deposit and dissemination of scientific research documents, whether they are published or not. The documents may come from teaching and research institutions in France or abroad, or from public or private research centers.
L'archive ouverte pluridisciplinaire HAL, est destinée au dépôt et à la diffusion de documents scientifiques de niveau recherche, publiés ou non, émanant des établissements d'enseignement et de recherche français ou étrangers, des laboratoires publics ou privés. 


\title{
ULTRASONIC CHARACTERIZATION OF POROSITY USING THE KRAMERS-KRONIG RELATIONS
}

\author{
J.H. ROSE, D.K. HSU AND L. ADLER+ \\ Ames Laboratory, USDOE, IOWa State University, Ames, \\ Iowa 50011, U.S.A. \\ + Welding Engineering Department, ohio state University. \\ Columbus, onio 43210 , U.S.A.
}

Abstract - A new algorithm is proposed to determine the volume fraction of pores in solids using the frequency dependent ultrasonic attenuation. The algorithm was developed by examining the Kramers-Kronig relation between the porosity induced ultrasonic attenuation and the change in sound velocity. The method is tested using data measured for several porous aluminum samples.

\section{I - INTRODUCTION}

This paper is structured as follows. First, a model is given which relates the porosity induced attenuation and the shift in the sound speed. Algorithms for the volume fraction, $c$, and the average pore size, a, are then derived. Finally, these algorithms are tested and found to be satisfactory using experimental attenuations measured in porous cast aluminum samples.

Porosity is modeled as a uniform random distribution of spherical voids of various radi $i$ in an otherwise homogeneous and isotropic elastic solid. The volume fraction is assumed small $(c \rightarrow 0$, practically $c<5 \%)$. Following recent treatments of this model (in particular Ref. 1), we obtain

$$
\alpha(k)=\frac{2 \pi}{k} \int_{0}^{\infty} d a n(a) \operatorname{ImA}(k, a)
$$

and

$$
\frac{\Delta V(k)}{V_{0}}=-\frac{2 \pi}{k^{2}} \int_{0}^{\infty} d a n(a) \operatorname{ReA}(k, a)
$$

Here $\alpha, \Delta V$ and $V_{0}$ are respectively the attenuation, the velocity shift and, the velocity of longitudinal sound in pore free material, for a longitudinally polarized displacement field. Also $n(a)$ da denotes the number of pores per unit volume with radii between $a$ and $a+d a$. The wave vector is denoted by $k$. $A(k, a)$ denotes the longitudinal to longitudinal forward scattering amplitude. 

The expression of causality in the frequency domain (Kramers-Kronig relations) ${ }^{2}$
implies

$$
\frac{\operatorname{Re} A(k)}{k^{2}}=\frac{1}{\pi} f_{-\infty}^{\infty} \frac{\operatorname{ImA}\left(k^{\prime}\right) d k^{\prime}}{k^{\prime 2} \cdot\left(k^{\prime}-k\right)}
$$

ard a similar relation for $\operatorname{ImA}(k) / k^{2}$. The slash indicates the principal part of the integral. Substitution of (3) in (2) yields

$$
\frac{\Delta V(k)}{V_{0}}=-\frac{1}{\pi} f_{-\infty}^{\infty} \frac{\alpha\left(k^{\prime}\right) d k^{\prime}}{k^{\prime}\left(k^{\prime}-k\right)}
$$

an expression familiar from other contexts; see for example Ref. 3.

The long wavelength limit of the velocity shift [Eq. (4)] leads to our basic result. As $k \rightarrow 0$, Eq. (4) becomes

$$
\frac{\Delta V(k=0)}{V_{0}}=-\frac{2}{\pi} \int_{0}^{\infty} \frac{\alpha\left(k^{\prime}\right) d k^{\prime}}{k^{\prime 2}}
$$

On intuitive ground $\Delta V(k \rightarrow 0)$ is $(1)$ expected to depend linearly on $c$ as $c \rightarrow 0$ and (2) to be independent of the pore size distribution. Consequently Eq.

(5) can be converted into an algorithm for determining $c$ from $\alpha(k)$.

We proceed by evaluating $E q$. (2) directly in the long wavelength limit. As $k \rightarrow$ $0, \operatorname{Re} A(k, a)=a\left(A_{2} k^{2} a^{2}+0\left(k^{4} a^{4}\right)\right)$. Here $A_{2}$ is a dimensionless expansion coefficient which depends only on the Poisson ratio of the host material. An analytic expression for $A_{2}$ can be obtained from Ref. 4. Substitution of the $k \rightarrow 0$ form of $\operatorname{Re} A(k)$ in Eq. (2) yields

$$
c=\frac{4}{3 \pi A_{2}} \int_{0}^{\infty} \frac{\alpha\left(k^{\prime}\right)}{k^{\prime 2}} d k^{\prime} .
$$

This is our basic algorithm. It determines $c$ from $\alpha(k)$ in a way which does not depend explicitly on the pore size distribution.

Once $c$ has been determined from Eq. (6), a rough estimate of the average pore size can be obtained. At high frequencies (ka>>1) the attenutation can be computed from an acoustic ray picture. It becomes $\alpha(k \rightarrow \infty)=N \pi\left\langle a^{2}\right\rangle$. Here $N$ is the total number of pores per unit volume. The average cross-sectional area per pore is given by $\pi\left\langle a^{2}\right\rangle$; where $\langle\ldots\rangle$ denotes the expectation value over the size distribution. On the other hand $c=4 \pi N\left\langle a^{3}\right\rangle / 3$. Combining those results yields the estimate $\bar{a}=\left\langle a^{3}\right\rangle /\left\langle a^{2}\right\rangle=3 C /(4 \alpha(k+\infty))$. We expect $\bar{a}$ to provide a reasonable estimate for the radius, if the distribution is sharply peaked about a mean value.

\section{EXPERIMENTAL RESULTS}

A number of samples of $A 357$ cast aluminum alloy with varying degrees of porosity (1-5\%) were produced at the OSU foundry. The flat samples were immersed in water and a wide-band ultrasonic pulse was scattered from them at normal incidence. The ratio of the back-surface to the front-surface echo allowed the estimation of $\alpha(k)$. Diffraction effects were accounted for. Details are given in Ref. 5 . 


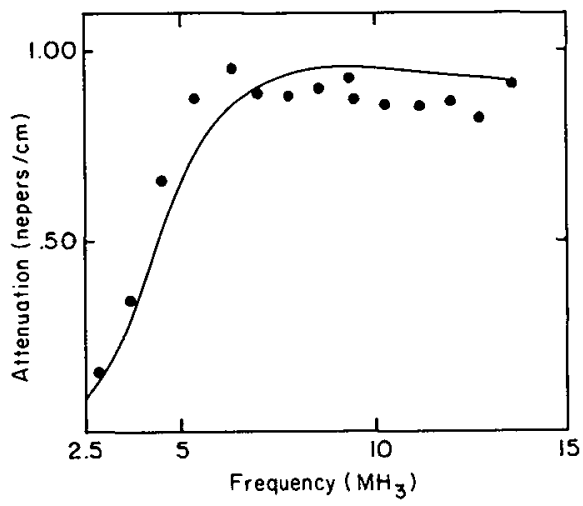

Fig. 1A. Shows experimental (...) and theoretical attenuation $(\longrightarrow)$ of Sample \#1510.

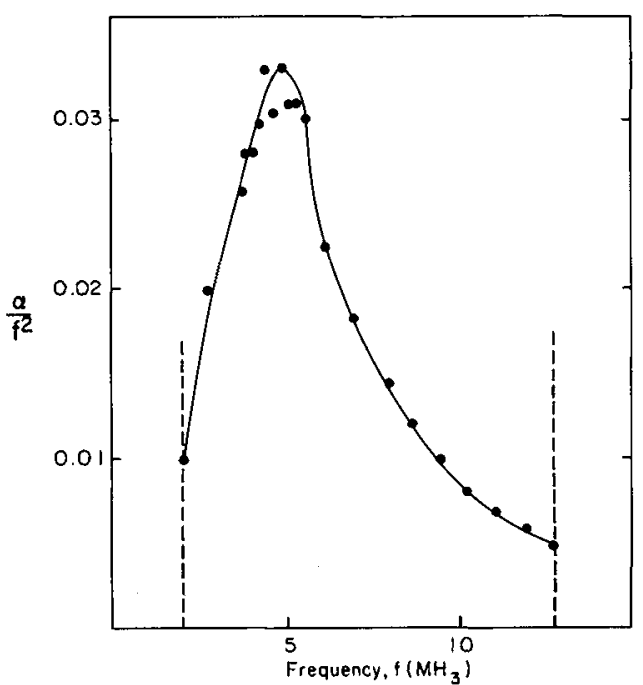

Fig. 1B. Shows integrand in Eq. (6). Vertical dashed lines indicate minimum and maximum usable frequencies (\#1510).

Table 1. Gives sample \#, actual c (density measurement), $\bar{c}$ (ultrasonic experiment), and radius estimate, $\bar{a}$.

\begin{tabular}{llcc}
\hline$\#$ & $c$ & $\bar{c}$ & $\bar{a}(\mu \mathrm{m})$ \\
1510 & .021 & .019 & 190 \\
1810 & .009 & .014 & 120 \\
1820 & .011 & .016 & 130 \\
1830 & .012 & .017 & 140 \\
1920 & .039 & .047 & 170 \\
\hline
\end{tabular}

Figure (1A) shows the experimental attenuation measured for sample 1510 . Figure (1B) shows a plot of $\alpha(k) / k^{2}$; the integrand in Eq. (6). The evaluation of the integral from 0 to o requires that the data be extended using prior information. The known asymptotic form of $\alpha(k)$ leads us (1) to set $\alpha(k)=\alpha\left(k_{\max }\right)$ for wavevectors $k>\left(k_{\max }\right)$; and $(2)$ to let $\alpha(k) \sim k^{4}$ for $k$ less than the smallest usable wavevector. These extensions typically account for $20 \%$ of the total integral. Finally $A_{2}$ $=.57$ for $A 357$ aluminum alloy.

Results are listed for a variety of samples in Table 1 . The trends indicate relatively good qualitative agreement between theory and experiment. The origin of the discrepancies are uncertain. However the assumptions that (1) the pores are spherical and (2) distributed uniformly in space are only approximate. The removal of these assumptions is expected to improve the currently good qualitative agreement. 


\section{ACKNOWLEDGEMENT}

This work was sponsored by the Center for Advanced Nondestructive Evaluation, operated by the Ames Laboratory, USDOE, for the Air Force Wright Aeronautical Laboratories/ Materials Laboratory under Contract No. W-7405-ENG-82 with Iowa State University.

\section{REFERENCES}

/1/Gubernatis, J. E. and Domany, E., Review of Progress in Quantitative Nondestructive Evaluation, 2A, 833 (1983).

/2/Newton, R. G., Scattering Theory of Waves and Particles, (Springer-Verlag, 1982).

/3/Beltzer, A. I. and Brauner, N., J. Acoust. Soc. Am. 76, 962 (1984).

/4/Ying, C. F. and Truel1, R., J. Appl. Phys. 27, 1086 (1956).

$15 /$ Wang, S.W., Csakany, A., Adler, L. and Mobley, C., Review of Progress in Quantitative Nondestructive Evaluation, 4B, 919 (1985). 